\title{
ECOLOGY-ECONOMICAL ASSESSMENT OF NEW RECLAMATION METHOD FOR CURRENTLY WORKING TECHNOGENIC MASSIFS
}

\author{
Alexey Strizhenok' ${ }^{1}$ Pavel Tcvetkov ${ }^{1}$ \\ 1 Saint-Petersburg Mining University, Vasilyevsky Island, 21st line 2, 199106 Saint-Petersburg, Russia, e-mail: \\ alexeystrizhenok@mail.ru, pscvetkov@yandex.ru
}

Received: 2016.08 .18

Accepted: 2016.10.23

Published: 2017.01.01

\begin{abstract}
One of the most relevant problems of the mining industry is the need to reduce the negative impact of technogenic massifs formed by wastes of extraction and processing of mineral raw materials. This problem has a significant meaning for currently used massifs, because traditional ways of reclamation are not suitable for them. The article describes the results of a scientific study on the development of the most efficient reclamation method for currently used technogenic massifs. Described in detail the main results of the field observations, methods and equipment of laboratory experiments conducted to determine agro-chemical properties of the soil and optimal composition of binder agent. The article also provides ecological and economic assessment of the proposed method of reclamation. The study was conducted on the example of the real technogenic massif, formed by wastes of phosphorus ore processing.
\end{abstract}

Keywords: technogenic massif, environment, waste, pollution, reclamation, bitumen emulsion, hydroseeding

\section{INTRODUCTION}

Every year the world mines about 100 billion tons of mineral resources. It leads to accumulation of solid and liquid waste in environment with annual volume more than 17 billion tons [Kozlov et al. 2015]. Despite high environmental risk of these wastes and the possibility of use as a secondary raw material [Teslya et al. 2015], the major method of their utilization is ground storage in the form of technogenic massifs [Strizhenok and Korelskiy 2015].

The area of lands disturbed by storing of mining and processing wastes in 2015, in Russia amounted more than 5 million hectares. This has led to deterioration of sanitary conditions in the residential areas within a radius of several dozen kilometers from the technogenic massifs, to increasing of morbidity and mortality of the population in these areas [Cherepovitsyn et al. 2015].

Moreover, on the areas with storages of mining wastes observed a decrease of animals and plants species diversity [State report 2015], dis- turbance and modification of the natural landscape and loss of relative renewable natural resources [Cherepovitsyn and Tcvetkov 2016].

This problem has a significant meaning for currently used massifs, because traditional ways of reclamation are not suitable for them. The surface of currently working massifs is renewed regularly, and the height of the massif is growing constantly. These factors cause the increase in the specific area discharging pollutants into the air [Didenko et al. 2015]. Moreover, the increase in the volume of technogenic massif leads to increase in the load on the Earth's surface, and the amount of atmospheric waters infiltrating through the solid body in the underground aquifers.

Thus, traditional methods of reclamation are low effective for currently working technogenic massifs, and, as a rule, are not economically effective. In this context, the development of an efficient and economically reasonable way to their reclaiming is an urgent scientific task [Golovanov et al. 2015]. 


\section{MATERIALS AND METHODS}

The main methods of research were: system analysis of fundamental scientific works of Russian and foreign scientists on this subject; monitoring, landscape-geochemical, bioindicative, experimental and analytical works in the field and laboratory with a using of modern scientific instrument base.

Soil samples in the area of technogenic massif to determine agrochemical characteristics were taken in accordance with standard "Sampling of soils" [GOST 28168-89] and standard "Methods of soil sampling and sample preparation for chemical, bacteriological, helminthological analysis" [GOST 17.4.4.02-84].

Testing of the durability characteristics of binder reagent was carried out in accordance with standard "Petroleum bitumens. Method for determination of depth of needle penetration" [GOST 11501-78], standard "Petroleum bitumen. Method for determination of ductility" [GOST 11505-75] and standard "Petroleum bitumen. The method of the determination of softening point by ring and ball" [GOST 11506-73].

The whole scientific instrumental base for carrying out field surveys, for chemical analysis of collected soil samples and for testing of the binder reagent durability characteristics were given by the laboratory of Environmental monitoring of the Saint-Petersburg Mining University [Scientific instrument base 2016].

The main methods of chemical analysis of soils samples were $\mathrm{x}$-ray fluorescence and atomic absorption methods. It allowed to establish their qualitative and quantitative composition, as well as agrochemical properties of soils, which formed the massif [Fedorec et al. 2009].

To determine the stability of the protective membrane to aggressive natural environmental conditions the climate chamber Q-SUN XE-3 was used.

\section{Details of laboratory experiments}

Dusting surfaces of technogenic massif, which is periodically renewed, is reclaimed by physic-chemical method by fixing soil with binding reagent, which has sufficient durability properties (not less than $0.2 \mathrm{MPa}$ ) to resist the destructive effects of wind.

The enterprise (object of the research) use lignosulfonate solution as a binding agent. This binding agent has sufficient strength in cold period of the year. However, its strength and durability reduced greatly during the warm period (4.5 months per year) under the influence of solar radiation. It increases the frequency of processing dusty surfaces, and therefore, annual costs of this process.

The analysis of existing experience of fixing dusty surfaces of alluvial massifs showed that the most acceptable method of temporarily fixing is processing of surface with anionic bitumen emulsion [Olejnikov et al. 1989]. With this in mind, in laboratory experiments were determined the concentration (in terms of bitumen weight ratio) and consumption of anionic bitumen emulsion solution to obtain a satisfactory quality of the protective membrane. In experiment was used an anionic bitumen emulsion EBA-3.

For application of fixing reagents was used spray gun. It has the next principle of action. Part of the compressed air, supplied to the spraying, is directed into a calibrated vessel with fixing agent. Pulp squeeze into a spray bottle under created pressure. Then it dispersed by air at the surface of the sample. Amount of dispersed solution was monitored by a gauge scale.

For physic-chemical analysis of soil fixing, we used next methods:

- determination of the durability characteristics with penetration method by the press-on dynamometer (minimum load, causing the destruction of the protective layer by needle $\mathrm{d}=0.5 \mathrm{~mm}$ ),

- determination of the infiltration time (time of forming a protective layer, s);

- determination of the infiltration depth (thickness of the protective layer, $\mathrm{cm}$ );

- determination of the hydraulic resistance through the change of durability after flooding;

- determination of the hydraulic conductivity of the layer, $\mathrm{m} /$ day;

- determination of the layer weather resistance through the change of durability.

Weather resistance tests were made in a climate chamber Q-SUN XE-3. Tests include exposure of artificial light (close to the sun), irrigation by water and establishment of temperature conditions. Samples were tested in 50 alternate cycles of wetting and drying by quartz lamp at $40^{\circ} \mathrm{C}$. The protective layer of the dried in natural conditions samples were tested on durability [Environmental camera Q-SUN Xe-March 2016]. 


\section{Economic evaluation}

As a rule, reclamation is unprofitable activity. Given this fact, for economic effectiveness evaluation was used method of comparing of the proposed reclamation technology and reclamation technology used by the enterprise today.

The main expenses selected for comparison are: costs for raw materials (bitumen emulsion and lignosulfonate) and payments for the emissions of pollutants (inorganic dust). Implementation of new reclamation technology will not require new equipment and additional human resources. The results of experiments and observations were taken as initial data for evaluation (Table 1).

The legislation of Russia provides different tax rates for normative, limit (agreed for a certain period) and above-limit emissions. The total amount of environmental payments could be calculated by formula 1 .

$$
\begin{gathered}
P=k_{r e g} *\left(T_{n} * E_{n}+T_{n} * k_{l} *\left(E_{l}-E_{n}\right)+\right. \\
\left.+T_{n} * k_{\boldsymbol{b}} *\left(E_{\boldsymbol{b}}-E_{l}\right)\right),
\end{gathered}
$$

where: $P$ - total amount of environmental payments, RUR;

$k_{\text {reg }}$ - regional increasing coefficient (for the region of research -1.4 );

$T_{n}$ - tax rate for normative emission (for inorganic dust - $21 \mathrm{RUR} /$ ton);

$E_{n}, E_{l}, E_{a l}$ - normative, limit and abovelimit emissions (fact amount), ton;

$k_{l}$ - increasing coefficient for limit emission (5 units);

$k_{a l}$ - increasing coefficient for above-limit emission (25 units).

At the same time, it is possible that the enterprise have no confirmed normative and limit amount of emission. In this case, the total amount of environmental payments is calculated by a maximum tax rate $\left(T_{n}^{*} k_{a l}\right)$.

The evaluation of financial effectiveness of the proposed technology was carried out on the basis of discounted cash flow method. Given the current unstable economic situation in the coun- try, the minimal discount rate should be taken at the level of $17 \%$ (inflation + key rate of the Bank of Russia) [Kozlov et al. 2016]. However, in view of the fact that this is non-profit project, discount rate could be changed depending on the vision of the company's management [Ponomarenko et al. 2016]. In this regard, calculation was made for rates of $15 \%, 20 \%, 25 \%$ and $30 \%$ for 5 -years period.

\section{RESULTS AND DISCUSSION}

The explored massif is alluvial technogenic massif, formed by wastes of phosphorus ore dressing process. Its total area is $7.8 \mathrm{~km}^{2}$.

The analysis of existing methods of fixing and reclamation of technogenic massif's dusty surfaces, as well as authors' field observations allowed to establish the need for implementation of reclamation in 2 stages. First - biological stage for area of massif with not renewing surface. Second - physic-chemical stage for area of massif with periodically renewing surface.

The biological reclamation is more difficult, but more durable, because it is done for the whole entire period of the massif operation. Chemical analysis of soil samples showed that the main minerals of massif are $\mathrm{SiO}_{2}(40-45 \%)$, $\mathrm{Al}_{2} \mathrm{O}_{3}(15-17 \%), \mathrm{Na}_{2} \mathrm{O}(9-10 \%), \mathrm{CaO}(6-7 \%)$, $\mathrm{K}_{2} \mathrm{O}(4,5-5 \%)$ и $\mathrm{P}_{2} \mathrm{O}_{5}(1-1,5 \%)$.

Phosphorus, potassium and calcium are the most important elements, which play a significant role in plant nutrition. Our agrochemical study showed that:

1) Potassium migrates in the soil solution easily and is in the form digestible by plants. Consequently, during the biological reclamation of this territory there is no need in adding additional potash fertilizer.

2) Phosphates contained in these soils are inaccessible to most plants. It is connected with partial dissolution of aluminum oxide, which interact with converted in the pore solution of phosphorus oxide. As a result, it compounds a

Table 1. Results of experiments and observations

\begin{tabular}{|l|c|c|c|}
\hline \multicolumn{1}{|c|}{ Indicator } & Unit & Using bitumen emulsion & Using lignosulfonate \\
\hline The problem area of technogenic massif & $\mathrm{Ha}$ & 200 & 200 \\
\hline $\begin{array}{l}\text { Minimal number of processing per year } \\
\text { (in optimal climatic conditions) }\end{array}$ & number & 2 & 3 \\
\hline Expenditure & $\mathrm{l} / \mathrm{m}^{2}$ & 1.5 & 2 \\
\hline
\end{tabular}


difficultly soluble aluminum phosphate. However, some forms of plants are able to extract up to $50-60 \%$ of the phosphorus contained in these soils.

3) Soil requires enrichment by organic matter, which play an important role not only in plant nutrition, but also in creating a favorable water regime. Enrichment of the substrate in organic matter can be achieved by introduction of large doses of biologically active organic fertilizer - manure and compost, peat, chopped straw or sawdust. The thickness of these substances layer should be $3-5 \mathrm{~cm}$. In addition, given that the soil does not contain nitrogen, the plants need additional ammonium nitrate in amount of $150 \mathrm{~kg} / \mathrm{ha}$.

The main success of the biological reclamation depends on preliminary preparation of the surface, the timely introduction of nitrogen and phosphate fertilizers, and proper selection of plants [Kapel'kina 1993]. From perennial grasses, the preference in the process of biological reclamation of disturbed lands should be given to sand-elymus as the most resistant plants on sandy soils.Thus, nepheline refinement tailings are favorable substrate for biological reclamation and creation of conditions for fixing the surface layer.
Biological reclamation should be carried out in the following sequence:

1) Uniform application of the peat layer, and then, two weeks before planting sand-elymus, mineral fertilizers - double superphosphate (1.5-2 $\mathrm{cwt} / \mathrm{ha}$ ) and ammonium nitrate (4 cwt/ha).

2) Sand-elymus must be sowed from mid-September till severe frosts with continuous line of planting and seeding depth of $1.5-3 \mathrm{~cm}$, with the following rolling and harrowing. sand-elymus seeding rate is $30-35 \mathrm{~kg} / \mathrm{ha}$.

3) To maintain sufficient height of grass, which provides erosion control function, it is necessary to make fertilizer at the same amounts as before the biological reclamation every spring after regrowth of grass during first 2-3 years [Ljubimova et al. 1970].

The results of the EBA-3 durability characteristics tests with different content of binder and bitumen are presented in Table 2 .

Experimental studies have shown that optimum fixing conditions are achieved by using an anionic bitumen emulsion containing $10 \%$ of bitumen and consumption rate of fixing solution at $1.5 \mathrm{l} / \mathrm{m}^{2}$. These options allow to form the protective membrane on the surface of the massif with durability 0.204-0.216 MPa. Such membrane has

Table 2. The results of the EBA-3 durability characteristics tests

\begin{tabular}{|c|c|c|c|}
\hline \multicolumn{3}{|c|}{ Fixing conditions } & \multirow{3}{*}{$\begin{array}{l}\text { Relative durability of the } \\
\text { solution (including solar } \\
\text { radiation effect) }\end{array}$} \\
\hline \multicolumn{2}{|c|}{ Composition of fixing solution } & \multirow{2}{*}{$\begin{array}{l}\text { Consumption } \\
\text { of fixing solution, } 1 / \mathrm{m}^{2}\end{array}$} & \\
\hline The content of the emulsion, $\%$ & The content of the bitumen, $\%$ & & \\
\hline 10 & $\sim 5(4.87)$ & \multirow{4}{*}{1.25} & 0.45 \\
\hline 20 & $\sim 10(9.74)$ & & 0.72 \\
\hline 30 & $\sim 15(14.61)$ & & 0.85 \\
\hline 40 & $\sim 20(19.48)$ & & 0.95 \\
\hline 10 & $\sim 5(4.87)$ & \multirow{4}{*}{1.50} & 0.55 \\
\hline 20 & $\sim 10(9.74)$ & & 1.05 \\
\hline 30 & $\sim 15(14.61)$ & & 1.05 \\
\hline 40 & $\sim 20(19.48)$ & & 1.07 \\
\hline 10 & $\sim 5(4.87)$ & \multirow{4}{*}{1.75} & 0.55 \\
\hline 20 & $\sim 10(9.74)$ & & 1.02 \\
\hline 30 & $\sim 15(14.61)$ & & 1.05 \\
\hline 40 & $\sim 20(19.48)$ & & 1.07 \\
\hline 10 & $\sim 5(4.87)$ & \multirow{4}{*}{2.00} & 0.56 \\
\hline 20 & $\sim 10(9.74)$ & & 1.02 \\
\hline 30 & $\sim 15(14.61)$ & & 1.05 \\
\hline 40 & $\sim 20(19.48)$ & & 1.05 \\
\hline
\end{tabular}

* - under "relative" means the durability determined by the method of penetration, which taken relative to durability equivalent to $0.200 \mathrm{MPa}$ under pressure. 
weather resistance, and is not destroyed during the seasonal period of dusting. Moreover, the pollution of water by emulsifier and bitumen after interaction with membrane is not detected.

As a result of anionic bitumen emulsion use, the dusting volume will be reduced from 249 (with lignosulfonate) to 8 tons per year. At the same time, only 86 tons of dust emission are normative and there are no confirmed limit amount of emission. The annual payment for 249 tons of dust emission is 122333.4 RUR, and for 8 tons -235.2 RUR (based on the calculation by formula 1).

The calculation of financial resources economy was carried out on the base of information presented in Table 1. The results showed that the annual cost for the purchase and use of lignosulfonate is $180 \mathrm{mln}$.RUR, whereas the use of a bitumen emulsion is $60 \mathrm{mln}$ RUR.

Predictive economic effect from replacement of the lignosulfonate on the bitumen emulsion and the dusting reduce on the five-year period is shown in Figure 1.
As noted above, the determination of the discount rate for the evaluation of the project is ambiguous task. Therefore, we evaluate the influence of four factors on the project annual economic effect (Figure 2): lignosulfonate price change, bitumen emulsion price change, change of the rate for normative emission (Tn, Formula 1 ), area change (with changes only in amount of necessary reagents).

The greatest impact on the economic effect cause the change of lignosulfonate price. The minor effect cause the change of tax rate for normative emission, due to its inadequately low value. The effect from changes in these factors showed in Table 3.

\section{CONCLUSION}

Proposed reclamation method is safe and effective in reducing the negative impact of technogenic massif on the air. The main advantage of the

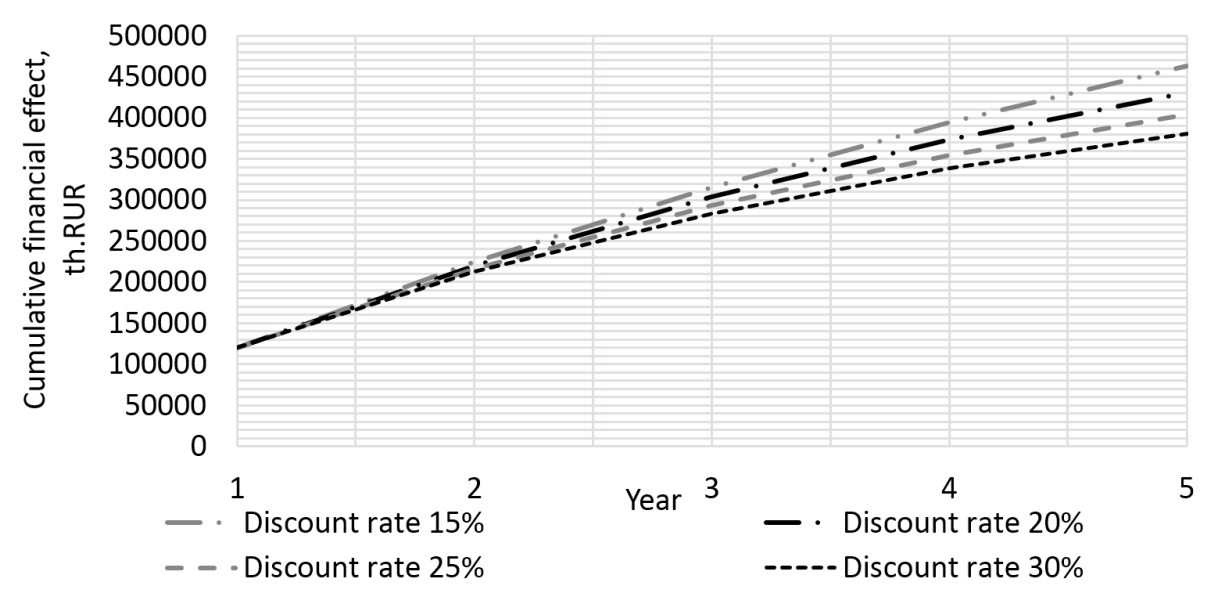

Figure 1. Predictive economic effect from replacement of the lignosulfonate on the bitumen emulsion

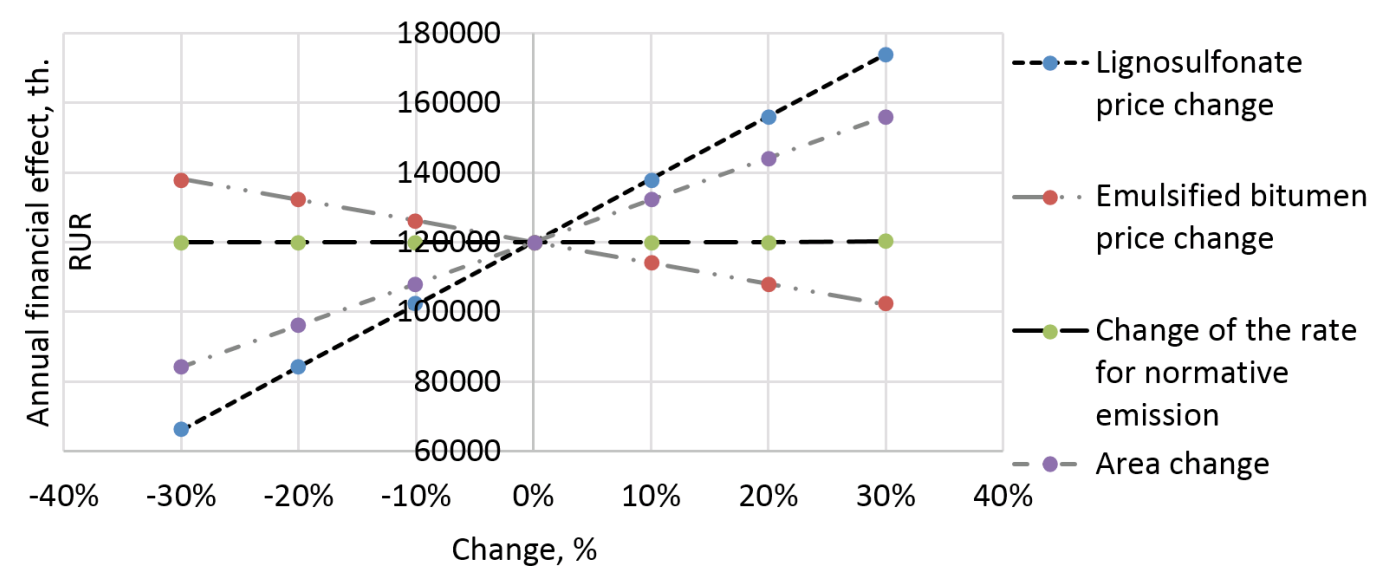

Figure 2. Relation between annual economic effect from the replacement of the lignosulfonate on the bitumen emulsion 
Table 3. The dependence of the economic effect from factors change

\begin{tabular}{|l|c|c|}
\hline \multicolumn{1}{|c|}{ Indicator } & $\begin{array}{c}\text { Change of } \\
\text { the factor }\end{array}$ & $\begin{array}{c}\text { Change of } \\
\text { financial effect }\end{array}$ \\
\hline Lignosulfonate price change & $+10 \%$ & $+14.99 \%$ \\
\hline $\begin{array}{l}\text { Bitumen emulsion price } \\
\text { change }\end{array}$ & $+10 \%$ & $-4.9 \%$ \\
\hline $\begin{array}{l}\text { Change of the rate for } \\
\text { normative emission }\end{array}$ & $+10 \%$ & $+0.01 \%$ \\
\hline Area change & $+10 \%$ & $+9.98 \%$ \\
\hline
\end{tabular}

proposed method of reclamation is that it can be used on currently working technogenic massifs. Calculations show that the use of the proposed method will significantly improve air quality in the residential areas located near the massif.

Experimental studies have shown that optimum fixing conditions are achieved by using an anionic bitumen emulsion containing $10 \%$ of bitumen and consumption rate of fixing solution at $1.5 \mathrm{l} / \mathrm{m}^{2}$. These options allow to form the protective membrane on the surface of the massif with durability $0.204-0.216 \mathrm{MPa}$.

The estimated economic effect shows the presence of a significant underlying strength of the project, which allows to implement it even in conditions of economic crisis.

\section{Acknowledgements}

The paper is based on research carried out with the financial support of the grant of the Russian Science Foundation (Project No. 14-3800009, "The program-targeted management of the Russian Arctic zone development"). Peter the Great St. Petersburg Polytechnic University.

\section{REFERENCES}

1. Cherepovitsyn A.E., Tsvetkov P.S. 2016. Methodical Approach to Evaluation of the Russian Peat Deposits Exploitation Attractiveness Based on Geology-Technological Criteria. International Journal of Applied Engineering Research, 11(7), 5072-5078.

2. Cherepovitsyn A.E., Fedoseev S.V., Teslya A.B., Vyboldina E.Y. 2015. Analysis of production and consumption of rare-earth metals in the EU and the BRICS. Tsvetnye Metally, (5), 5-10. DOI: 10.17580/tsm.2015.05.01

3. Didenko N., Kunze K., Skripnuk D. 2015. Russian Export Strategy and Social Sector: Consequences of Resource-Oriented Exports on Population of Russia. Mediterranean Journal of Social Sciences. Part. 6, No. 5. Supplement 2, 473-481.
4. Environmental camera Q-SUN Xe-3. The tests for lightfastness and weathering. URL: http://www. qualicont.ru/products/qlab/qsun/ (07.08.2016).

5. Fedorec N.G., Medvedeva M.V. 2009. The methodology of soil research of urbanized territories. Petrozavodsk: Karelian research centre of Russian Academy, pp. 84.

6. Golovanov A.I., Zimin F.M., Smetanin V.I. (2015) Reclamation of disturbed lands. "DEER" publisher, Moscow, pp. 336.

7. GOST 11501-78. Petroleum bitumens. Method for determination of depth of needle penetration (Russia). URL: http://vsegost.com/Catalog/46/4657. shtml (06.08.2016).

8. GOST 11505-75. Petroleum bitumen. Method for determination of ductility (Russia). URL: http://vsegost.com/Catalog/16/16661.shtml (06.08.2016).

9. GOST 11506-73. Petroleum bitumen. The method of the determination of softening point by ring and ball (Russia). URL: http://vsegost.com/Cata$\log / 83 / 8324 . s h t m l$ (06.08.2016).

10. GOST 17.4.4.02-84. Methods of soil sampling and sample preparation for chemical, bacteriological, helminthological analysis» (Russia). URL: http://vsegost.com/Catalog/29/29438.shtml (06.08.2016).

11. GOST 28168-89. Sampling of soils» (Russia). URL: http://vsegost.com/Catalog/38/38689.shtml (06.08.2016).

12. Kapelkina L.P. 1993. Environmental aspects of the optimization of technogenic massifs. Saint Petersburg. Science PROPO. pp. 190.

13. Kozlov A.V., Fedoseev S.V., Cherepovitsyn A.E., Gutman S.S., Zaichenko I.M., Marinina O.A., Rytova E.V., P.S. Tsvetkov, Tochilo M.V. 2016. Integrated development of the economic space of the Russian Arctic. Monograph, pp. 315.

14. Kozlov A., Gutman S., Zaychenko I., Rytova E., Nijinskaya P. (2015) Environmental management on the basis of Complex Regional Indicators Concept: Case of the Murmansk region. IOP Conference Series: Materials Science and Engineering, 91 (1). DOI: 10.1088/1757-899X/91/1/012073.

15. Lyubimova A.A., Medvedev P.M. 1970. Experience of fixing vegetation dusty tailings of ANOF-1 combine „Apatite”. Vegetation and industrial pollution. Sverdlovsk. Sciences of the USSR Publisher, 104-111.

16. Oleynikov A.G., Storozhenko N.D. 1989. Compositions for fixing dusty surfaces of technogenic massifs. Non-ferrous Metallurgy (scientific and technical journal) No. 10. Ore and Metals, pp. 61-64.

17. Ponomarenko T.V., Fedoseev S.V., Korotkiy S.V., Belitskaya N.A. 2016. Managing the Implementa- 
tion of Strategic Projects in the Industrial Holding. Indian Journal of Science and Technology, 9(14), DOI: $10.17485 / \mathrm{ijst} / 2016 / \mathrm{v} 9 \mathrm{i14} / 91517$.

18. Scientific instrument base of the laboratory of Environmental monitoring of the National Mineral Resources University (Mining University). URL: http://spmi.ru/nsciarticle/nsciarticle_13473 (06.08.2016).

19. State report 2015. On condition and protection of the environment of the Russian Federation in 2015. URL: http://www.ecogosdoklad.ru/2015/default. aspx (06.08.2016).

20. Strizhenok A.V., Korelskiy D.S. 2015. Assessment of the anthropogenic impact in the area of tailings storage of the apatite-nepheline ores. Pollution Research, 34(4), 809-811.

21. Teslya A., Cherepovitsyn A., Vyboldina E., Fedoseev S., Kozmenko S. 2015. The concept of economic growth of the construction industry in St. Petersburg. MATEC Web of Conferences, 53, 01005. DOI: dx.doi.org/10.1051/matecco$\mathrm{nf} / 20165301005$. 